\title{
HIV associated high-risk HPV infection among Nigerian women
}

\author{
Sally N Akarolo-Anthony ${ }^{1,2^{*}}$, Maryam Al-Mujtaba ${ }^{2}$, Ayotunde O Famooto ${ }^{2}$, Eileen O Dareng ${ }^{2}$, Olayinka B Olaniyan ${ }^{3}$, \\ Richard Offiong ${ }^{4}$, Cosette M Wheeler ${ }^{5}$ and Clement A Adebamowo ${ }^{1,2,6}$
}

\begin{abstract}
Background: In developed countries, the incidence of cervical cancer has remained stable in HIV+ women but the prevalence and multiplicity of high-risk HPV (hrHPV) infection, a necessary cause of cervical cancer, appears different comparing HIV+ to HIV- women. Little is known about HIV and HPV co-infection in Africa.

Methods: We enrolled women presenting at our cervical cancer screening program in Abuja, Nigeria between April and August 2012, and collected information on demographic characteristics, risk factors of HPV infection and samples of exfoliated cervical cells. We used Roche Linear Array HPV Genotyping Test ${ }^{\varpi}$ to characterize prevalent HPV and logistic regression models to estimate the association between HIV and the risk of hrHPV infection.

Results: There were 278 participants, 54\% (151) were HIV+, 40\% (111) were HIV-, and 6\% (16) had unknown HIV status. Of these, data from $149 \mathrm{HIV}+$ and $108 \mathrm{HIV}$ - women were available for analysis. The mean ages $( \pm \mathrm{SD})$ were $37.6( \pm 7.7)$ years for HIV+ and $36.6( \pm 7.9)$ years for HIV- women ( $p$-value = 0.34$)$. Among the HIV+ women, HPV35 (8.7\%) and HPV56 (7.4\%) were the most prevalent hrHPV, while HPV52 and HPV68 (2.8\%, each) were the most prevalent hrHPV types among HIV- women. The multivariate prevalence ratio for any hrHPV and multiple hrHPV infections were $4.18(95 \% \mathrm{Cl} 2.05-8.49$, $p$-value <0.0001) and $6.6(95 \% \mathrm{Cl} 1.49-29.64, p$-value 0.01$)$ respectively, comparing HIV + to HIV- women, adjusted for age, and educational level.

Conclusions: HIV infection was associated with increased risk of any HPV, hrHPV and multiple HPV infections. Oncogenic HPV types 35, 52, 56 and 68 may be more important risk factors for cervical pre-cancer and cancer among women in Africa. Polyvalent hrHPV vaccines meant for African populations should protect against other hrHPV types, in addition to 16 and 18.
\end{abstract}

Keywords: HIV, HPV, Nigeria

\section{Background}

Human papillomavirus (HPV) is the most common sexually transmitted infection and at least $50 \%$ of sexually active people will get HPV at some time in their lives[1,2]. More than $100 \mathrm{HPV}$ genotypes have been identified based on the sequence of their L1 genes [1,3]. HPV are classified into high-risk, probable high-risk and low-risk types, based on HPV-type-specific odds ratios and HPV prevalence among groups of women with cervical cancer and their controls [4]. HPV types 16, 18, 31, 33, 35, 39,

\footnotetext{
* Correspondence: sna094@mail.harvard.edu

'Department of Nutrition, Harvard School of Public Health, 677 Huntington

Avenue, Boston, MA 02115, USA

${ }^{2}$ Office of Strategic Information and Research Department, Institute of

Human Virology Nigeria, 252 Herbert Macaulay Way, Abuja, Nigeria

Full list of author information is available at the end of the article
}

$45,51,52,56,58,59,68,73$, and 82 are considered highrisk HPV (hrHPV) [4,5]. In addition to already established types, the International Agency for Cancer Research (IARC) recently classified HPV39, 59, 51 and 56 as carcinogenic while HPV68, 26, 30, 34, 53, 66, 67, 69, $70,73,82$ and 85 were classified as possibly carcinogenic $[6,7]$, but this classification has been criticized for lack of supporting epidemiological data [8]. The classification of HPV types according to their oncogenic potential is an ongoing process and is dependent on availability of data from different parts of the world.

Persistent hrHPV infection is recognized as a necessary but not sufficient cause for Cervical Intraepithelial Neoplasm (CIN) grades $2 / 3$ and cervical cancer [9]. Molecular genetic studies of hrHPV from most parts of the world

\section{Biomed Central}


suggest that types 16 and 18 are the most prevalent types associated with CIN2 + [10,11]. This has been supported by several meta-analyses [8,12]. However these studies contained few high quality data from Africa and their results are liable to be biased by the availability and source of data. In the latest meta-analysis for example, inclusion of data from Eastern Asia inflated the prevalence of HPV58 suggesting that similar situation may occur as more data accrue from other parts of the world [9,10,13-17].

Although the limited data available suggests that the incidence and mortality from cervical cancer in Africa has not changed significantly in the last few decades despite the HIV/AIDS epidemic [18-21], HIV infection may result in different HPV distributions in cancer, within sub-Saharan Africa [22]. Several studies show that HIV+ women are more likely to be infected with non-16 and non-18 hrHPV types including HPV51, 53 and 56 as well as with multiple infections [23,24]. Studies done in Africa to date suggest that the most prevalent hrHPV types are HPV16, 52, 53 and 58 in HIV+ women, compared to HPV52 and 51 in HIV- women [16,25,26]. However, these studies were based on East African populations, in Uganda, Rwanda and Zambia. There is scarce data about the prevalent hrHPV among HIV+ women in West African populations. One study found the most prevalent types of hrHPV among women in Abidjan, Cote d'Ivoire to be HPV16 and 35, regardless of HIV status [27]. Given that cervical cancer incidence is $\sim 50 \%$ higher in East compared to West Africa $[28,29]$ we hypothesized that the prevalence, types and multiplicity of

Table 1 Characteristics of the study population, by HIV status

\begin{tabular}{|c|c|c|c|c|c|}
\hline \multirow[t]{2}{*}{ Characteristics } & \multirow{2}{*}{$\frac{\text { HIV positive }(n=149)}{\text { Mean }( \pm S D)}$} & \multirow{2}{*}{$\frac{\text { HIV negative }(n=108)}{\text { Mean }( \pm S D)}$} & \multirow{2}{*}{$\frac{\text { HIV positive }(n=149)}{N(\%)}$} & \multirow{2}{*}{$\frac{\text { HIV negative }(n=108)}{\mathrm{N}(\%)}$} & \multirow[t]{2}{*}{ p-value } \\
\hline & & & & & \\
\hline $\mathrm{Age}^{\#}$ & $36.6( \pm 7.9)$ & $37.6( \pm 7.7)$ & & & 0.34 \\
\hline Age categories" & & & & & 0.30 \\
\hline$-\leq 30$ & & & $35(23.7)$ & $23(21.3)$ & \\
\hline$-31-36$ & & & $44(29.7)$ & $22(20.4)$ & \\
\hline$-37-44$ & & & $47(31.7)$ & $44(40.7)$ & \\
\hline$-\quad \geq 45$ & & & $22(14.9)$ & 19 (17.6) & \\
\hline Age at sexual initiaton ${ }^{\#}$ & $20.8( \pm 4.4)$ & $19.2( \pm 3.9)$ & & & 0.004 \\
\hline Age at sexual initiation ${ }^{\#}$ & & & & & 0.005 \\
\hline$-\quad<18$ & & & $41(28.7)$ & $21(19.4)$ & \\
\hline$-18-21$ & & & $68(47.5)$ & $50(46.3)$ & \\
\hline$-22-25$ & & & $26(18.2)$ & $16(14.8)$ & \\
\hline$->25$ & & & $8(5.6)$ & $21(19.5)$ & \\
\hline Total sex partners & $3.3( \pm 3.2)$ & $3.9( \pm 5.5)$ & & & 0.34 \\
\hline Total sex partners & & & & & 0.54 \\
\hline-1 & & & $35(23.7)$ & $34(31.5)$ & \\
\hline$-2-3$ & & & $68(46.0)$ & $40(37.0)$ & \\
\hline$-4-5$ & & & $27(18.2)$ & $18(16.7)$ & \\
\hline$-5+$ & & & $18(8.1)$ & $15(13.8)$ & \\
\hline Education & & & & & 0.002 \\
\hline$-\quad \leq 6$ years & & & $28(18.8)$ & $7(6.5)$ & \\
\hline - Secondary & & & $104(69.8)$ & $76(70.4)$ & \\
\hline - Tertiary & & & $17(11.4)$ & $25(23.1)$ & \\
\hline Marital Status & & & & & $<0.001$ \\
\hline - $\quad$ Married, \% & & & $76(51.0)$ & $82(75.9)$ & \\
\hline - $\quad$ Not married, \% & & & $73(49.0)$ & $26(24.1)$ & \\
\hline Condom use* & & & & & 0.26 \\
\hline - Yes & & & $3(2.0)$ & $0(0)$ & \\
\hline - No & & & $146(98.0)$ & 108 (100) & \\
\hline
\end{tabular}


Table 2 Prevalence of specific high-risk HPV types by HIV status, among Nigerian women

\begin{tabular}{lllc}
\hline $\begin{array}{l}\text { HrHPV } \\
\text { type }\end{array}$ & $\begin{array}{l}\text { HIV positive [n= 149] } \\
\mathbf{N}(\%)\end{array}$ & $\begin{array}{l}\text { HIV negative [n= 108] } \\
\mathbf{N}(\%)\end{array}$ & $\mathbf{p}$-value \\
\hline 16 & $5(3.4)$ & $1(0.9)$ & 0.41 \\
18 & $5(3.4)$ & $2(1.9)$ & 0.70 \\
31 & $3(2.0)$ & $1(0.9)$ & 0.64 \\
33 & $6(4.0)$ & $0(0.0)$ & 0.04 \\
35 & $13(8.7)$ & $0(0.0)$ & $<0.001$ \\
39 & $4(2.7)$ & $2(1.9)$ & 1.0 \\
45 & $7(4.7)$ & $2(1.9)$ & 0.31 \\
51 & $4(2.7)$ & $0(0.0)$ & 0.14 \\
52 & $3(2.0)$ & $3(2.8)$ & 0.69 \\
56 & $11(7.4)$ & $1(0.9)$ & 0.01 \\
58 & $10(6.7)$ & $0(0.0)$ & 0.006 \\
59 & $8(5.4)$ & $1(0.9)$ & 0.08 \\
68 & $5(3.4)$ & $3(2.8)$ & 1.0 \\
\hline
\end{tabular}

hrHPV infections might differ between East and West African populations and are likely to be associated with the rates of cervical cancer in these populations.

\section{Methods}

\section{Study population}

Between April and August 2012, we enrolled 278 women from 3 cervical cancer screening clinics at National Hospital Abuja and University of Abuja Teaching Hospital, Nigeria. All the study participants were 18 years or older, had prior vaginal sexual intercourse, not pregnant and had an intact uterus. Interviewer administered questionnaires were used to collect data on socio-demographic characteristics, HIV status, sexual and reproductive history. Participants HIV status were confirmed from their medical records. Trained nurses performed pelvic examinations on all the study participants. Samples of exfoliated cervical cells were obtained from the cervical os using Ayres spatula and stored at $-80^{\circ} \mathrm{C}$, until processing for HPV genotyping.

\section{HPV detection by genotyping}

HPV DNA genotyping was done using linear array to HPV genotyping test (Roche Diagnostics), a qualitative in vitro test which utilizes amplification of target DNA by the Polymerase Chain Reaction (PCR) and nucleic acid hybridization and detects 37 high- and low-risk HPV genotypes [30]. The Linear Array HPV genotyping test has been validated and offers reliable and sensitive approach for detecting HPV DNA in cervical specimens, using standardized quality-controlled reagents [31-35].

\section{Data management}

Data was managed using REDCap electronic data capture tools, hosted at the Institute of Human Virology, Nigeria (IHVN) [36,37].

\section{Statistical analysis}

A total of 278 participants were enrolled in this study. We excluded 16 persons whose HIV status were not confirmed and 5 persons who had missing data on HPV genotype or several demographic variables. Descriptive analyses were performed to characterize the sampled population. $t$-tests were used to assess differences in the distribution of continuous variables between groups, while $x^{2}$ and Fishers exact tests were used for categorical variables. Multivariate logistic regression models were conducted to examine the association between HIV status and risk of hrHPV infections. All analyses were performed using SAS 9.3 for UNIX statistical software (SAS Institute, Cary, NC, USA).

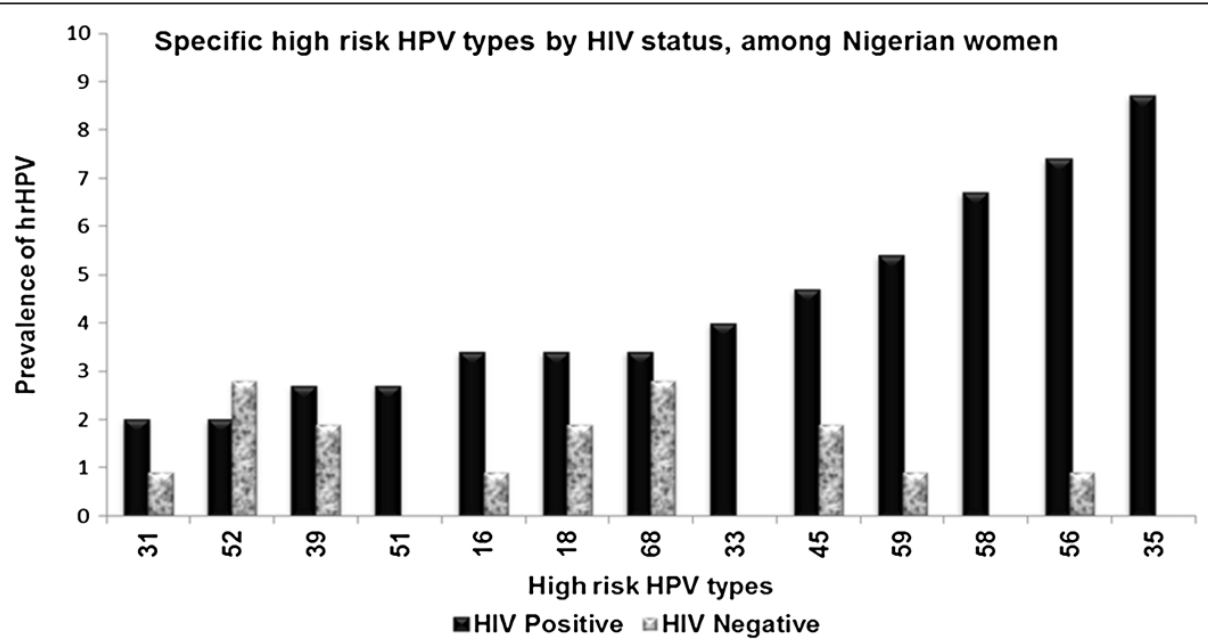

Figure 1 Frequency of high risk HPV types among Nigerian women, by HIV status. 


\section{Ethics}

The study was conducted according to the Nigerian National Code for Health Research Ethics and the Declaration of Helsinki. Ethical approval to conduct this study was obtained from the IHVN health research ethics committee. Informed consent was obtained from all participants before enrollment in the study.

\section{Results}

We analyzed data on 257 women, of whom 58\% (149/ 257) were $\mathrm{HIV}+$ and $42 \%(108 / 257)$ were HIV-. The mean age and standard deviation $( \pm S D)$ of the participants was $36.6( \pm 7.9)$ years for the HIV+ and $37.6( \pm 7.7)$ years for the HIV- women. Half (51\%) of the HIV+ women were married, compared to $76 \%$ of the HIVwomen who were married. The mean age at sexual initiation was $20.8( \pm 4.4)$ years for the HIV+ women, compared to $19.2( \pm 3.9)$ for the HIV-women, $p$-value $=0.004$. $\mathrm{HIV}+$ and HIV- women did not differ by total number of sexual partners or consistent condom use. Table 1 describes the demographic characteristics of the study participants by HIV status.

The prevalence of hrHPV infection was 25\% (64/257). Among the HIV+ women, 36\% (53/149) had hrHPV infections, while $10 \%(11 / 108)$ of the HIV- women had hrHPV infections $(p=<0.001)$. Thirteen specific hrHPV types were detected among the HIV+ women and 9 hrHPV types among the HIV- women. HPV33, 35, 51 and 58 were detected only among the HIV+ women. The most prevalent hrHPV type in the study population was HPV35; it was detected exclusively in HIV+ women, where it accounted for 24.5\% (13/53) of the hrHPV infections. HPV33, 51 and 58 were also detected only in the HIV+ women. The prevalence of HPV types 35, 56 and 58 were significantly different among HIV+ compared with HIV- women (Table 2). Figure 1 shows the specific hrHPV types among the women, by HIV status

We found single hrHPV infections were more common $66 \%$ (42/64), compared to multiple hrHPV infections 34\% $(22 / 64)$ in the overall study population $(p=<0.001)$. Among the HIV+women, 14\% (21/149) had multiple hrHPV infections while $2 \%(2 / 108)$ of the HIV- women had multiple hrHPV infections $(p=<0.001)$. Of the $21 \mathrm{HIV}$ + women infected with multiple hrHPV genotypes, 15 were infected with two, 5 were infected with three and 1 was infected with six hrHPV types. All the HIV+ women infected with 2 hrHPV types had HPV35 and another type.

The age adjusted prevalence ratio (PR) of any instance of single hrHPV infection and any instance of multiple hrHPV infection comparing $\mathrm{HIV}+$ women to HIVwomen were 4.71 (95\% CI 2.34 - 9.46, $p=<0.001)$ and 8.68 (95\% CI $1.99-37.96, p=<0.004$ ) respectively. The multivariate PR of any hrHPV and multiple hrHPV infection adjusted for age and education were 4.18 (2.06 - 8.49 $p=<0.001)$ and $6.66(1.50-29.64 p=0.01)$ respectively. Education accounted for most of the variation in these multivariate models (Table 3).

\section{Discussion and conclusion}

Our study shows that the prevalence of hrHPV infection was significantly higher among HIV+ women, compared to HIV- women and HIV+ women were more likely to have multiple hrHPV infections. In decreasing order, HPV35, 56, 58, 59 and 45 were the most prevalent types of hrHPV infection found among those who were HIV+ while HPV68, 52, 39, 45 and 18 were the most prevalent types of hrHPV infection among those who were HIV-, in our study participants.

Table 3 Prevalence ratios and 95\% confidence intervals of high-risk HPV infections, among Nigerian women

\begin{tabular}{|c|c|c|c|c|c|}
\hline & & \multicolumn{2}{|c|}{ Single high risk HPV } & \multicolumn{2}{|c|}{ Multiple high risk HPV } \\
\hline & & PR $(95 \%$ Cl) & $p$-value & PR $(95 \%$ Cl) & $p$-value \\
\hline \multirow[t]{3}{*}{ Model 1} & HIV (Ref = HIV negative) & $4.18(2.06-8.49)$ & $<0.001$ & $6.66(1.50-29.64)$ & 0.01 \\
\hline & Age & $0.94(0.90-0.98)$ & 0.001 & $0.95(0.89-1.01)$ & 0.10 \\
\hline & Education & $0.58(0.32-1.04)$ & 0.06 & $0.29(0.12-0.70)$ & 0.006 \\
\hline \multirow[t]{4}{*}{ Model 2} & HIV (Ref = HIV negative) & $4.76(2.28-9.93)$ & $<0.001$ & $7.97(1.80-35.29)$ & 0.006 \\
\hline & Age & $0.93(0.89-0.97)$ & 0.001 & $0.95(0.89-1.01)$ & 0.08 \\
\hline & No. of sexual partners & $0.91(0.65-1.28)$ & 0.58 & $0.80(0.48-1.34)$ & 0.40 \\
\hline & Age at sexual initiation & $0.94(0.66-1.35)$ & 0.74 & $0.71(0.40-1.26)$ & 0.23 \\
\hline \multirow[t]{6}{*}{ Model 3} & HIV (Ref = HIV negative) & $4.38(2.06-9.30)$ & 0.001 & $5.93(1.29-27.14)$ & 0.02 \\
\hline & Age & $0.93(0.89-0.97)$ & 0.001 & $0.95(0.89-1.01)$ & 0.11 \\
\hline & Education & $0.64(0.34-1.21)$ & 0.17 & $0.31(0.12-0.81)$ & 0.02 \\
\hline & Marital status & $1.03(0.53-2.01)$ & 0.93 & $1.82(0.68-4.87)$ & 0.23 \\
\hline & No. of sexual partners & $0.93(0.65-1.32)$ & 0.68 & $0.78(0.45-1.33)$ & 0.36 \\
\hline & Age at sexual initiation & $1.00(0.69-1.45)$ & 0.99 & $0.91(0.50-1.64)$ & 0.74 \\
\hline
\end{tabular}


Our results are consistent with the findings from other studies that showed women with HIV infection were more likely to be infected with non-16 and non-18 hrHPV types $[24,38,39]$. The most prevalent types of hrHPV found in this study differ from those in other populations. Among $208 \mathrm{HIV}+$ non-pregnant women in São Paulo, Brazil and 229 HIV+ non-pregnant women in New York, US, the most common types of hrHPV were 51, 18, 16 and 56, 53, 16, 58 respectively [23,24]. Among HIV+ pregnant women in Thailand, the most common hrHPV types were 39, 52, 53 and 16 [39]. In Africa, a study among HIV+ and HIV- women in Kampala, Uganda found the most prevalent types of hrHPV to be 52, 16 and 58, and these where similar to findings in Nairobi, Kenya [25,40]. In Kigali, Rwanda, the most prevalent hrHPV type among HIV+ women was also HPV52, followed by HPV51 and 58 [16].

Our findings were similar to the results from other studies in Nigeria. Cage et al. found non-16 and non-18 HPV were the most prevalent hrHPV types [41]; Okolo et al. found HPV35 was as prevalent as HPV16; Musa et al. found the prevalence of hrHPV among HIV+ women was $45 \%$ [42]. Lifestyle factors such as sociocultural characteristics, nutritional, environmental, sexual behavior and hygiene, vaginal microbiota and genetic factors, along with specific geographic distribution of hrHPV types may explain the varying prevalence of hrHPV and cervical cancer incidence across populations. The incidence $(52.8$ per 100,000$)$ of cervical cancer in Zambia, East Africa is $~ 50 \%$ higher than in Nigeria, West Africa where the incidence is 34.5 per 100,000 $[18,28,29]$. The differences in the prevalent types of hrHPV in West and East Africa, may partly explain these regional variations in cervical cancer incidence.

Other studies, like ours, found a high prevalence of multiple hrHPV infections among HIV+ women $[16,24-27,38,39]$. The full spectrum of hrHPV types that are involved in multiple infections, their persistence, individual and relative contribution to oncogenicity and duration of persistence of the different hrHPV types in the context of multiple infections in African women is not known. The etiological and preventative significance of multiple infections and its potential impact on current vaccination and HPV DNA based testing strategies are also not entirely clear and should be assessed in different populations [16,17].

Differences in epidemiology of hrHPV between developed and developing countries may be meaningful, given that the current and next generations of HPV vaccines do not include some of the types that are prevalent in Africa. This will be particularly significant if there is little or no antibody cross-reactivity between current vaccines and the hrHPV types prevalent in Africa [8]. Given the high prevalence of non-16 and non-18 hrHPV among
HIV+ women in Nigeria and other African countries, current vaccines may have limited impact in this section of the population. Longitudinal investigations of HPV genotype-specific risks for cervical precancer and cancer outcomes should be conducted in Africa. As the incidence of cervical cancer among HIV+ women has increased in the combination Antiretroviral Therapy era, there is a need for further studies examining the role of covariates of persistent hrHPV infection such as sexual behavior, sexual hygiene, diet, smoking, alcohol consumption, concurrent genital tract infections, other illnesses and sexual partner health behavior in cervical carcinogenesis.

\section{Abbreviations}

Cl: Confidence interval; CIN: Cervical intraepithelial neoplasm; HIV+: HIV positive; HIV: HIV negative; HPV: Human papillomavirus; hrHPV: high-risk HPV; IARC: International Agency for Cancer Research; IHVN: Institute of Human Virology Nigeria; PCR: Polymerase chain reaction; PR: Prevalence ratio.

\section{Competing interests}

CMW has received through the University of New Mexico, funds from grants and cooperative agreements from the US National institutes of Health related to cervical screening, funds from GSK for HPV vaccine studies and reimbursements for travel related to publication activities and equipment and reagents from Roche Molecular Systems for HPV genotyping. Other authors report no conflicts of interest.

\section{Authors' contributions}

SNA analyzed the data and drafted the manuscript. MA, AOF, and EOD contributed to the study coordination. $\mathrm{OO}$ and RU, site investigators, contributed to the study design, implementation and provided revisions of the manuscript. CMW performed HPV genotyping, contributed to data

interpretation and provided revisions of the manuscript. CAA conceived the study, obtained funds, contributed to the study design and provided critical revisions of the manuscript. All authors read and approved the final manuscript.

\section{Acknowledgement}

This work was supported by the UM-Capacity Development for Research in AIDS Associated Malignancy Grant (NIH/NCl 1D43CA153792-01) to CAA. HPV genotyping was supported by NIAID U19 Al084081 to CMW.

\section{Study design}

Cross-sectional survey.

\section{Author details}

'Department of Nutrition, Harvard School of Public Health, 677 Huntington Avenue, Boston, MA 02115, USA. ${ }^{2}$ Office of Strategic Information and Research Department, Institute of Human Virology Nigeria, 252 Herbert Macaulay Way, Abuja, Nigeria. ${ }^{3}$ Department of Obstetrics and Gynecology, National Hospital, Abuja, Nigeria. ${ }^{4}$ University of Abuja Teaching Hospital, Gwagwalada, Abuja, Nigeria. ${ }^{5}$ Department of Pathology, University of New Mexico Health Sciences Center, Albuquerque, NM 87131, USA. 'Institute of Human Virology and Greenebaum Cancer Center, University of Maryland School of Medicine, Baltimore, MD 21201, USA.

Received: 8 July 2013 Accepted: 29 October 2013

Published: 5 November 2013

\section{References}

1. Bernard HU, Burk RD, Chen Z, van Doorslaer K, Hausen H, de Villiers EM: Classification of papillomaviruses (PVs) based on 189 PV types and proposal of taxonomic amendments. Virology 2010, 401:70-79.

2. Human Papilloma Virus. http://www.cdc.gov/STD/HPV/STDFact-HPV.htm.

3. de Villiers EM, Fauquet C, Broker TR, Bernard HU, zur Hausen H: Classification of papillomaviruses. Virology 2004, 324:17-27.

4. Munoz N, Bosch FX, de Sanjose S, Herrero R, Castellsague X, Shah KV, Snijders PJ, Meijer CJ: Epidemiologic classification of human papillomavirus types associated with cervical cancer. N Engl J Med 2003, 348:518-527. 
5. Clifford GM, Gallus S, Herrero R, Munoz N, Snijders PJ, Vaccarella S, Anh PT, Ferreccio C, Hieu NT, Matos E, et al: Worldwide distribution of human papillomavirus types in cytologically normal women in the International Agency for Research on Cancer HPV prevalence surveys: a pooled analysis. Lancet 2005, 366:991-998.

6. Schiffman M, Clifford G, Buonaguro FM: Classification of weakly carcinogenic human papillomavirus types: addressing the limits of epidemiology at the borderline. Infect Agent Cancer 2009, 4:8.

7. Bouvard V, Baan R, Straif K, Grosse Y, Secretan B, El Ghissassi F, BenbrahimTallaa L, Guha N, Freeman C, Galichet L, et al: A review of human carcinogensPart B: biological agents. Lancet Oncol 2009, 10:321-322.

8. Li N, Franceschi S, Howell-Jones R, Snijders PJ, Clifford GM: Human papillomavirus type distribution in 30,848 invasive cervical cancers worldwide: variation by geographical region, histological type and year of publication. Int J Cancer 2011, 128:927-935.

9. Bodily J, Laimins LA: Persistence of human papillomavirus infection: keys to malignant progression. Trends Microbiol 2011, 19:33-39.

10. Smith JS, Melendy A, Rana RK, Pimenta JM: Age-specific prevalence of infection with human papillomavirus in females: a global review. $J$ Adolesc Health 2008, 43:S5-25. S25 e21-41.

11. Guan P, Howell-Jones R, Li N, Bruni L, de Sanjose S, Franceschi S, Clifford GM: Human papillomavirus types in 115,789 HPV-positive women: a metaanalysis from cervical infection to cancer. Int J Cancer 2012, 131:2349-2359.

12. Smith JS, Lindsay L, Hoots B, Keys J, Franceschi S, Winer R, Clifford GM: Human papillomavirus type distribution in invasive cervical cancer and high-grade cervical lesions: a meta-analysis update. Int J Cancer 2007, 121:621-632.

13. Denny L, Anorlu R: Cervical cancer in Africa. Cancer Epidemiol Biomarkers Prev 2012, 21:1434-1438.

14. Louie KS, de Sanjose S, Mayaud P: Epidemiology and prevention of human papillomavirus and cervical cancer in sub-Saharan Africa: a comprehensive review. Trop Med Int Health 2009, 14:1287-1302.

15. Safaeian M, Kiddugavu M, Gravitt PE, Gange SJ, Ssekasanvu J, Murokora D, Sklar M, Serwadda D, Wawer MJ, Shah KV, Gray R: Determinants of incidence and clearance of high-risk human papillomavirus infections in rural Rakai, Uganda. Cancer Epidemiol Biomarkers Prev 2008, 17:1300-1307.

16. Veldhuijzen NJ, Braunstein SL, Vyankandondera J, Ingabire C, Ntirushwa J, Kestelyn E, Tuijn C, Wit FW, Umutoni A, Uwineza M, et al: The epidemiology of human papillomavirus infection in HIV-positive and HIV-negative high-risk women in Kigali, Rwanda. BMC Infect Dis 2011, 11:333.

17. Woodman CB, Collins S, Winter H, Bailey A, Ellis J, Prior P, Yates M, Rollason TP, Young LS: Natural history of cervical human papillomavirus infection in young women: a longitudinal cohort study. Lancet 2001, 357:1831-1836.

18. Ferlay J, Shin HR, Bray F, Forman D, Mathers C, Parkin DM: GLOBOCAN 2008 v2.0, Cancer Incidence and Mortality Worldwide. In Book GLOBOCAN 2008 v2.0, Cancer Incidence and Mortality Worldwide (Editor ed.^eds.). City: International Agency for Research on Cancer; 2010.

19. Klint A, Tryggvadottir L, Bray F, Gislum M, Hakulinen T, Storm HH, Engholm G: Trends in the survival of patients diagnosed with cancer in female genital organs in the Nordic countries 1964-2003 followed up to the end of 2006. Acta Oncol 2010, 49:632-643.

20. Mbulaiteye SM, Bhatia K, Adebamowo C, Sasco AJ: HIV and cancer in Africa: mutual collaboration between HIV and cancer programs may provide timely research and public health data. Infect Agent Cancer 2011, 6:16.

21. Parkin DM, Ferlay J, Hamdi-Cherif M, Sitas F, Thomas JO, Wabinga H, Whelan SL: Cancer in Africa: epidemiology and prevention. Lyon: IARCPress; 2003.

22. Ndiaye C, Alemany L, Ndiaye N, Kamate B, Diop Y, Odida M, Banjo K, Tous S, Klaustermeier JE, Clavero O, et al: Human papillomavirus distribution in invasive cervical carcinoma in sub-Saharan Africa: could HIV explain the differences? Trop Med Int Health 2012, 17:1432-1440.

23. Levi JE, Kleter B, Quint WG, Fink MC, Canto CL, Matsubara R, Linhares I, Segurado A, Vanderborght B, Neto JE, Van Doorn LJ: High prevalence of human papillomavirus (HPV) infections and high frequency of multiple HPV genotypes in human immunodeficiency virus-infected women in Brazil. J Clin Microbiol 2002, 40:3341-3345.

24. Luque AE, Jabeen M, Messing S, Lane CA, Demeter LM, Rose RC, Reichman RC: Prevalence of human papillomavirus genotypes and related abnormalities of cervical cytological results among HIV-1-infected women in Rochester, New York. J Infect Dis 2006, 194:428-434.

25. Blossom DB, Beigi RH, Farrell JJ, Mackay W, Qadadri B, Brown DR, Rwambuya S, Walker CJ, Kambugu FS, Abdul-Karim FW, et al: Human papillomavirus genotypes associated with cervical cytologic abnormalities and HIV infection in Ugandan women. J Med Virol 2007, 79:758-765.

26. Sahasrabuddhe W, Mwanahamuntu MH, Vermund SH, Huh WK, Lyon MD, Stringer JS, Parham GP: Prevalence and distribution of HPV genotypes among HIV-infected women in Zambia. Br J Cancer 2007, 96:1480-1483.

27. Jaquet A, Horo A, Charbonneau V, Ekouevi DK, Roncin L, Toure B, Coffie P, Minga A, Sasco AJ, Garrigue I, et al: Cervical human papillomavirus and HIV infection in women of child-bearing age in Abidjan, Cote d'Ivoire, 2010. Br J Cancer 2012, 107:556-563.

28. Ferlay J, Shin HR, Bray F, Forman D, Mathers C, Parkin DM: Estimates of worldwide burden of cancer in 2008: GLOBOCAN 2008. Int J Cancer 2010, 127:2893-2917.

29. Jedy-Agba E, Curado MP, Ogunbiyi O, Oga E, Fabowale T, Igbinoba F, Osubor G, Otu T, Kumai H, Koechlin A, et al: Cancer incidence in Nigeria: a report from population-based cancer registries. Cancer Epidemiol 2012, 36:e271-278.

30. Cooksley CD, Hwang LY, Waller DK, Ford CE: HIV-related malignancies: community-based study using linkage of cancer registry and HIV registry data. Int J STD AIDS 1999, 10:795-802.

31. Castle PE, Sadorra M, Garcia F, Holladay EB, Kornegay J: Pilot study of a commercialized human papillomavirus (HPV) genotyping assay: comparison of HPV risk group to cytology and histology. J Clin Microbiol 2006, 44:3915-3917.

32. Coutlee F, Rouleau D, Petignat P, Ghattas G, Kornegay JR, Schlag P, Boyle S, Hankins C, Vezina S, Cote P, et al: Enhanced detection and typing of human papillomavirus (HPV) DNA in anogenital samples with PGMY primers and the Linear array HPV genotyping test. J Clin Microbiol 2006, 44:1998-2006.

33. Stevens MP, Rudland E, Garland SM, Tabrizi SN: Assessment of MagNA pure LC extraction system for detection of human papillomavirus (HPV) DNA in PreservCyt samples by the Roche AMPLICOR and LINEAR ARRAY HPV tests. J Clin Microbiol 2006, 44:2428-2433.

34. van Hamont D, van Ham MA, Bakkers JM, Massuger LF, Melchers WJ: Evaluation of the SPF10-INNO LiPA human papillomavirus (HPV) genotyping test and the roche linear array HPV genotyping test. J Clin Microbiol 2006, 44:3122-3129.

35. Stevens MP, Garland SM, Tabrizi SN: Validation of an automated detection platform for use with the roche linear array human papillomavirus genotyping test. J Clin Microbiol 2008, 46:3813-3816.

36. Franklin JD, Guidry A, Brinkley JF: A partnership approach for electronic data capture in small-scale clinical trials. J Biomed Inform 2011, 44(Supplement 1):S103-S108.

37. Harris PA, Taylor R, Thielke R, Payne J, Gonzalez N, Conde JG: Research electronic data capture (REDCap)—A metadata-driven methodology and workflow process for providing translational research informatics support. J Biomed Inform 2009, 42:377-381.

38. McKenzie ND, Kobetz EN, Hnatyszyn J, Twiggs LB, Lucci JA 3rd: Women with HIV are more commonly infected with non-16 and -18 high-risk HPV types. Gynecol Oncol 2010, 116:572-577.

39. Bollen $\amalg$, Chuachoowong R, Kilmarx PH, Mock PA, Culnane M, Skunodom N, Chaowanachan T, Jetswang B, Neeyapun K, Asavapiriyanont S, et al: Human papillomavirus (HPV) detection among human immunodeficiency virus-infected pregnant Thai women: implications for future HPV immunization. Sex Transm Dis 2006, 33:259-264.

40. De Vuyst H, Steyaert S, Van Renterghem L, Claeys P, Muchiri L, Sitati S, Vansteelandt S, Quint W, Kleter B, Van Marck E, Temmerman M: Distribution of human papillomavirus in a family planning population in nairobi, kenya. Sex Transm Dis 2003, 30:137-142.

41. Gage JC, Ajenifuja KO, Wentzensen NA, Adepiti AC, Eklund C, Reilly M, Hutchinson M, Wacholder S, Harford J, Soliman AS, et al: The age-specific prevalence of human papillomavirus and risk of cytologic abnormalities in rural Nigeria: implications for screen-and-treat strategies. Int J Cancer 2012, 130:2111-2117

42. Musa J, Taiwo B, Achenbach C, Olugbenga S, Berzins B, Sagay AS, Idoko JA, Kanki PJ, Murphy RL: High-risk human papillomavirus among HIV-infected women with normal cervical cytology: a pilot study in Jos, Nigeria. Arch Gynecol Obstet 2013

doi:10.1186/1471-2334-13-521

Cite this article as: Akarolo-Anthony et al:: HIV associated high-risk HPV infection among Nigerian women. BMC Infectious Diseases 2013 13:521. 